\title{
Introduction
}

So as technology hurtles forward, we must think back to that legacy [Universal Declaration of Human Rights]. We need to synchronize our technological progress with our principles ... Today, we find an urgent need to protect these freedoms on the digital frontiers of the 21 st century.

(Clinton 2010)

\section{THE INTERNET AND HUMAN RIGHTS}

The human rights implications of internet use have been subject to debate since the mid-1990s, yet recently the agenda has taken on a new momentum. ${ }^{1}$ Over the past couple of years civil society, academics, policy makers and companies practically compete to highlight the role of the internet as a tool for social change with policy implications in a number of spheres.

At the beginning of 2011 the uprisings in North Africa and the Middle East gave rise to the term 'Facebook revolution', indicating the role that social media played as a resource to organize and distribute information amongst the individuals and groups opposing the regime. ${ }^{2}$ During the uprisings various restrictions were imposed on internet access in several countries, and subsequently the former Egyptian president and two of his officials were fined US\$90m for cutting internet and mobile phone communications (UPI 28 May 2011). At a gathering in Copenhagen in May 2011 a number of the participating bloggers, activists, writers, and so on, shared their stories and debated the role of the internet in the revolution. ${ }^{3}$ At that meeting several of the speakers stressed that while the revolution

1 By the internet I am referring to a global information and communication system that is linked together via the TCP/IP protocol (Federal Networking Council Resolution 1995).

2 See, for example, the coverage in The Guardian (Naughton 23 January 2011). Also, the Iranian revolt in 2009 was spoken of as something that would not have happened without Twitter (Morozov 2011: 2-3).

3 Conference on Cyber Activism, 9 May 2011, in Copenhagen. Arranged by Kvinfo Information, available at: http://forside.kvinfo.dk/nyhed/arabiske-kvinderonline-og-i-front, retrieved 12 October 2012. The meeting was covered in the Danish newspaper Weekendavisen (Rifbjerg 13 May 2011). 
did not start in cyberspace, social media did provide an important platform for sharing information and mobilizing voices. As a consequence, internet freedom is now being debated as part of the new Egyptian Constitution. ${ }^{4}$

At policy level, the link between the internet and human rights has recently been on the agenda at several high-level meetings. At the 17th session of the United Nations (UN) Human Rights Council in June 2011, the UN for the first time debated a report specifically focused on the internet and the right to freedom of expression. The report produced by the UN Special Rapporteur on the promotion and protection of the right to freedom of opinion and expression addresses the opportunities and challenges that the internet poses to the right to freedom of expression (La Rue 2011). The report stresses that the internet has become an indispensable tool for realizing a range of human rights, combating inequality, and accelerating development and human progress. In consequence, ensuring universal access to the internet should be a priority for all states (La Rue 2011: para. 85). The report also emphasizes that censorship measures should never be delegated to private entities, and that intermediaries should not be held liable for refusing to take action that infringes individuals' human rights (La Rue 2011: para. 75). ${ }^{5}$ Subsequently the Swedish Minister of Foreign Affairs, on behalf of 41 states, supported the report and stressed that 'For us, one principle is very basic: The same rights that people have offline - freedom of expression, including the freedom to seek information, freedom of assembly and association, amongst others - must also be protected online' (Bildt 10 June 2011).

More or less at the same time, the internet was addressed in the Deauville Declaration: Internet, as an outcome of the G8 meeting in Paris. ${ }^{6}$ The Declaration stresses that the leaders commit to 'encourage the use of the Internet as a tool to advance human rights and democratic participation throughout the world' (Article 13). It also iterates that the principles of openness, transparency and freedom of the internet have been key to its development and success, and must, together with non-discrimination and fair competition, continue to be an essential force behind its development (Article 9). ${ }^{7}$ As part of the G8 meeting, the German Minister of Foreign

4 Speech by Lina Attalah, 9 May 2011, at the Conference on Cyber Activism in Copenhagen.

5 The report was prepared in consultation with a number of organizations, including civil society networks such as the Association for Progressive Communications (APC) and European Digital Rights (EDRI). See http://www.edri. org/edrigram/number9.11/un-report-online-censorship, retrieved 12 October 2012.

6 The Declaration is available at: http://www.g8.utoronto.ca/summit/2011 deauville/2011-internet-en.html, retrieved 12 October 2012.

7 The Declaration has been criticized by civil society groups for not recognizing the protection of human rights as core principles above all others, rather than 
Affairs spoke at length about freedoms in cyberspace, stressing that free access to the internet is a human right, and that freedom of expression and freedom of association are only protected in the twenty-first century if these rights are also valid in cyberspace. ${ }^{8}$

Most recently the UN Human Rights Council has by consensus adopted a resolution on the promotion, protection and enjoyment of human rights on the internet. Presented by Sweden, the resolution affirms that 'the same rights people have offline must also be protected online' (United Nations Human Rights Committee 5 July 2012).

The above examples highlight how policy makers increasingly embrace the notion of internet freedoms, and stress that these are essential to an internet based on human rights standards. ${ }^{9}$ At the same time, however, just as many attempts to increase control of the internet may be found, including in democratic countries. One example is the proposal of a virtual Schengen border around EU countries, in order to strengthen control over dissemination of information to and from European Union (EU) member states. ${ }^{10}$ The proposal suggests that European cyberspace should have 'virtual access points' and that internet service providers would block illicit content at these border points on the basis of an EU blacklist. Similar to physical roadblocks, access points are suggested in order to strengthen regional control over the flow of information into the EU region. The European Commission (EC) has refuted the assertion that the virtual Schengen border represents official EU policy, ${ }^{11}$ yet the security of European cyberspace is an ongoing policy issue within the EU.

On a similar note, scholars have claimed the 'Rise of a Cybered Westphalian Age' pointing to national and regional border-making in cyberspace:

including them in a framework to be balanced with the protection of intellectual property. See, for example, the ARTICLE 19 response available at: http:// www.article19.org/resources.php/resource/1774/en/g8-the-deauville-declarationon-internet-fails-to-recognise-importance-of-human-rights-including-freedom-ofexpression, retrieved 12 October 2012.

8 The speech was printed in the German newspaper Frankfurter Rundschau (Westerwelle 27 May 2011).

9 The notion of internet freedom has been contested for the cyber-utopianism and internet-centrism often associated with its use (Morozov 2011: 318).

10 See, for example, the coverage in EDRI-Gram 9.9, 4 May 2011, available at: http://www.edri.org/edrigram/number9.9/virtual-schengen-border, retrieved 12 October 2012.

11 In response to a question raised by Christian Engström, member of the European Parliament for Piratpartiet, Sweden, Commissioner Cecilia Malmström replied that the notion of a virtual EU border appeared in a presentation by a national delegate (Hungary) and was not to be interpreted as EU policy as such (European Commission 20 June 2011). 
From the Chinese intent to create their own controlled internal Internet, to increasingly controlled access to the Internet in less-democratic states, to the rise of Internet filters and rules in Western democracies, states are establishing the bounds of their sovereign control in the virtual world in the name of security and economic sustainability.

(Demchak et al. 2011: 32)

As a recent example of expanding national control in cyberspace, the Iranian government has announced the first phase of a national internet, also referred to as 'Our Own Internet', while blocking access to Google and Gmail. ${ }^{12}$ Moreover, in order to prevent and react to 'cyber warfare' (attacks on a country's digital infrastructure by another country) the USA and the EU have strengthened the military grip on the internet via the US Cyber Command (USCYBERCOM) and the European Network and Information Security Agency (ENISA) respectively. ${ }^{13}$

What may at a first glance look like increased support for internet freedoms is thus countered by at least as many examples of increased control of the internet. ${ }^{14}$ This is indicative of competing interests such as freedom versus control, but also indicates essentially different perspectives toward the internet. The debate on internet freedom is focused on the internet as a democratic space closely linked to human rights and social change. Participants in this discourse may easily agree upon the importance of internet policies that are respectful of human rights, and repeatedly condemn attempts to unduly restrict those freedoms - for example at the UN Human Rights Council. The debate on cyber security, by contrast, refers to the internet as a critical national infrastructure that needs to be secured and controlled in order to protect vital interests of society. Participants in this discourse are not ignorant of human rights, yet their primary concern lies with infrastructure protection, and with potential attacks on the stability of the internet, as addressed, for example, at the Military Cyber Security conference in Washington. ${ }^{15}$

This book argues that different framings of the internet highlight specific human rights issues. The book proposes four metaphors around which to organize our debate on human rights challenges in the internet era.

12 See the coverage by Reuters available at: http://www.reuters.com/article/2012/09/23/net-us-iran-internet-national-idUSBRE88M0AO20120923, retrieved 17 October 2012.

13 See http://www.enisa.europa.eu/ and http://www.defense.gov/home/features/ 2010/0410_cybersec/, retrieved 12 October 2012.

14 See MacKinnon (2012) for a wide list of examples of increased control over the internet.

15 See http://www.militarycybersecurity.com/, retrieved 12 October 2012. 
The themes are infrastructure, public sphere, medium, and culture. The infrastructure dimension focuses on the internet as a global resource that enables communication; the public sphere dimension highlights the internet as a public space; the media dimension draws attention to the internet as a new media platform; whereas the cultural dimension focuses on the internet's social norms and practices. The themes are not seen as exclusive; on the contrary, they coexist in policy as well as in scholarly debate. Each of them, however, highlights specific features of the internet and is associated with certain human rights challenges.

\section{BOOK OUTLINE}

The book consists of three main parts and a concluding chapter.

The first part outlines and critically examines the field of human rights in the information society. This comprises a brief introduction to the notion of an information society and to some of the scholars who have made contributions in this field, in particular scholars such as Castells and Luhmann. Next, the public and private distinction is explored, as well as how it relates to the themes of infrastructure, public sphere, medium and culture, respectively. The examination of public and private is included since internet policy challenges in many instances relate to various aspects of the internet as public and private. Finally, the human rights framework is presented, including an analysis of how human rights have intersected with ICT in four different spheres: civil society; the intergovernmental sphere; the business domain; and the research sphere.

In the second part the four suggested metaphors are outlined and debated. The metaphors are presented on the back of associated research themes and human rights issues related to that particular framing. The infrastructure metaphor focuses on the internet as a universal and nondiscriminatory resource; the public sphere metaphor on the new modalities for public and political life; the medium metaphor on the democratization of broadcasting and publishing; and the culture metaphor on the potential for a more participatory culture.

While the book's first two parts develop an analytical framework, the third, empirically oriented, part explores concrete spaces of internet-related social interaction, tracing the discursive, metaphoric frames that guide the involved actors' articulation of their agency. In particular, two empirical case studies (women's use of ICT in Uganda and the German Wikipedia community) are used to explore the implications of the actors' framing of these phenomena primarily in terms of the internet as public sphere and the internet as culture. Both cases address the means by which local groups 
deploy ICT for social change, ${ }^{16}$ while being essentially different on most parameters. The women's groups are situated in a developing country and seek to empower local women via use of conventional media as well as the internet, whereas Wikipedia is an online community of internet-savvy users with the declared goal of enhancing the public domain of knowledge in all languages of the world.

The concluding chapter will discuss the current state of affairs with regard to human rights protection in the internet era, present some crosscutting perspectives, and suggest areas for future research.

\section{INTERNET METAPHORS}

The notion of metaphors is inspired by the work of Krippendorff (1993) and Lakoff and Johnson (1980). In Metaphors We Live By, Lakoff and Johnson argue that the use of metaphors is pervasive in everyday life, in language, thought and action, and that our conceptual system is essentially metaphorical in nature. The essence of metaphors is to provide associational frameworks, enabling us to understand and experience one kind of thing in terms of another (Lakoff and Johnson 1980: 5). However, a metaphor is not merely the words used to talk about something - for example 'time is money', 'love is a journey', 'internet explorer' - but also the underlying logic or approach for addressing the issue. As stressed by Krippendorff, metaphors (1) carry explanatory structures from a familiar domain of experiences into an other domain in need of understanding and restructuring, (2) require seeing some structural similarities between these two domains, (3) have entailments for the target domain they thereby organize far beyond any initial structural similarity, and (4) organize their user's perceptions and, when acted upon, can create the realities experienced (Krippendorff 1993: 2-3). The notion of framing has both sociological and psychological foundations, but generally addresses the construction of meaning, for example via metaphors, exemplars, catchphrases, depictions, and visual images (Borah 2011: 249). By framing the internet as infrastructure, public sphere, medium and culture, respectively, the idea is to illuminate different associational frameworks from the target domain, and how these relate to specific human rights issues.

Several scholars have used metaphors to capture various features of the internet. In the internet's early days Stefik (1996) suggested four metaphors

16 Social change refers to a societal transition towards greater conformity with human rights standards. 
for thinking about the emerging 'information infrastructure', namely digital library (keeper of knowledge), electronic mail (communicator), electronic marketplace (trader), and digital worlds (adventurer) (Stefik 1996: $\mathrm{xx})$. Kurbalija, who has been closely involved in WSIS, speaks of internet analogies such as telephony, post, television, library, photocopier, highway, high seas, and of 'baskets' of internet governance policy issues. These baskets relate to the infrastructure of the internet; the use of the internet; issues with wider impact such as intellectual property rights; and issues related to the developmental aspects of the internet (Kurbalija 2010: 22-7). The cyberspace and market of ideas metaphors are addressed, amongst others, by Gandy and Farral in their examination of cases related to enforcement of property law in cyberspace. ${ }^{17}$ The authors argue that technically cyberspace is not a metaphor, but merely a merger of the two words cybernetics and space:

To say that the Internet is a 'library' or a 'town square' are metaphorical constructions that involve key entailments of a source domain (library, town square) that the receiver of the message can then map on to the target domain (the Internet). In the case of cyberspace, the entailments of this source domain, other than that it is some form of space, do not emerge from common experience.

(Gandy and Farral 2010)

The marketplace of ideas metaphor was widely used in policy making and judgments especially related to free speech cases, long before the advent of the internet. ${ }^{18}$ As pointed out by the authors, there is disagreement in the legal literature as to the specific role of metaphors, for instance the extent to which the use of metaphors constrains the thinking of the court or not (Gandy and Farral 2010: 351). As a final example, Andrade investigates how metaphors such as 'giant brains', 'information highways', 'metaverse', 'cyberspace' and 'ambient intelligence' contribute to the social acceptance and implementation of technology. Drawing on Flichy's analysis of how the utopian vision of the internet was shaped (Flichy 2007), the author argues that commonly accepted metaphors are used to create a societal identification with the technology available (Norberto Gomes de Andrade 2010: 43). ${ }^{19}$

17 See also Patry (2009) on metaphors used in the 'copyright war'.

18 The metaphor was first used by Justice Holmes in his dissenting opinion in the 1919 case Abrams v. United States, available at: http://www.law.cornell.edu/ supct/html/historics/USSC_CR_0250_0616_ZD.html, retrieved 12 October 2012.

19 Other examples of a metaphorical approach to the internet include Blavin and Cohen (2002) and Ratzan (2000). 
The four metaphors used to structure the analysis of this book are inspired by two sources in particular. First by a broad review of internetrelated literature covering communication and media studies, political science, and cultural studies. Secondly by a review of internet- and human rights-related policy discourses at the WSIS (2003-2005), at the IGF (2007 and 2009), within the EU, and at Council of Europe level. As part of this exercise, policy themes were mapped according to the human rights issues they highlighted, as illustrated in Table I.1.

As previously stressed, many competing internet-related metaphors exist; however, the four metaphors proposed here all show up in policy controversies related to social change/human rights. To give an example, the cyberspace metaphor entails no obvious connection to any specific human rights issues, whereas many human rights-related controversies relate to the public sphere metaphor (for example, access to participate in democratic life, violations of internet freedoms, participation of civil society, and so on). Obviously no one metaphor covers the multiple dimensions of the internet; however, each of them addresses specific features of the target domain, as further explained below.

The first metaphor, infrastructure, was used to characterize the internet from early on. As stressed by Stefik, the internet was originally called the 'national information infrastructure' in the USA and subsequently referred to as 'the information super highway' (Stefik 1996: xviii). When the internet (as the target domain) is referred to as an infrastructure (the source domain), it highlights that it is the basis for something else: an underlying resource in line with highways, railways or the postal system. At WSIS and the Internet Governance Forum (IGF) the infrastructure metaphor shows up in the policy debates related to, for example, the operation of the internet, that is specific themes and controversies related to coordinating and governing the internet's critical resources. As such, the infrastructure metaphor is closely related to the technology that carries the internet and that consists of various technical resources. Like other infrastructures, the internet's technical layer was constructed at a certain point in time, and is now operated and maintained on an ongoing basis. ${ }^{20}$ In terms of social change (human rights potential), the metaphor highlights the universal and non-discriminatory characteristics of the internet's technical layer.

The second metaphor, public sphere, is reflected in a policy and scholarly debate that addresses the internet as a space for democratic participation,

20 The responsibility for a number of tasks related to the daily management of the internet is vested with the US-based Internet Corporation for Assigned Names and Numbers (ICANN) on contract with the US government. The mandate and operation of ICANN was a controversial issue at WSIS, and led to the inception 
Table I.1 Mapping themes at the IGF in Sharm El Sheikh (2009)

\begin{tabular}{|c|c|c|c|}
\hline Thematic cluster* & Policy challenge & $\begin{array}{l}\text { Human rights issues } \\
\text { (not exhaustive) }\end{array}$ & $\begin{array}{l}\text { Proposed } \\
\text { metaphor }\end{array}$ \\
\hline Access and diversity & $\begin{array}{l}\text { How to ensure } \\
\text { an internet } \\
\text { for all }\end{array}$ & $\begin{array}{l}\text { Access to participate } \\
\text { online } \\
\text { Non-discrimination } \\
\text { Access to knowledge }\end{array}$ & $\begin{array}{l}\text { Public sphere } \\
\text { Culture }\end{array}$ \\
\hline $\begin{array}{l}\text { Security, openness and } \\
\text { privacy }\end{array}$ & $\begin{array}{l}\text { How to find the } \\
\text { right bal- } \\
\text { ance between } \\
\text { openness and } \\
\text { control on the } \\
\text { internet }\end{array}$ & $\begin{array}{l}\text { Internet security } \\
\text { Protection of online } \\
\text { freedoms } \\
\text { Protection of specific } \\
\text { audiences }\end{array}$ & $\begin{array}{l}\text { Infrastructure } \\
\text { Public sphere } \\
\text { Medium }\end{array}$ \\
\hline $\begin{array}{l}\text { Managing critical } \\
\text { internet resources }\end{array}$ & $\begin{array}{l}\text { How to operate } \\
\text { and manage } \\
\text { the internet } \\
\text { as a global } \\
\text { resource }\end{array}$ & $\begin{array}{l}\text { HR protection in } \\
\text { relation to a global } \\
\text { resource }\end{array}$ & Infrastructure \\
\hline $\begin{array}{l}\text { Internet governance } \\
\text { in the light of the } \\
\text { WSIS principles }\end{array}$ & $\begin{array}{l}\text { How to ensure a } \\
\text { people-centred } \\
\text { and inclusive } \\
\text { development } \\
\text { of the infor- } \\
\text { mation society }\end{array}$ & $\begin{array}{l}\text { Rights-based } \\
\text { approach to } \\
\text { internet policy and } \\
\text { regulation }\end{array}$ & Cross-cutting \\
\hline
\end{tabular}

Note: * See the Chairman's summary (Internet Governance Forum 2009).

including themes such as access, freedoms, and resources to participate. The metaphor highlights the internet's features as a public sphere and the new modalities for democratic life enabled by the internet. Moreover, it raises policy issues related to how resources necessary for communication are made available, and to whom. Themes of access, freedoms, and resources to participate were high on the WSIS agenda and have been equally prominent on the IGF agenda. ${ }^{21}$ With regard to social change, the public sphere metaphor points to the internet's potential for revitalizing democratic life, and in providing new mechanisms and tools for civil society groups.

of the Internet Governance Forum (IGF) as a global platform to discuss a broad range of issues pertaining to internet governance.

${ }_{21}$ IGF is organized as an annual four-day meeting with a mixture of plenary debates, workshops, exhibitions, and so on. The themes are recurring topics from the WSIS process such as access, openness, security, capacity building, and critical internet resources. See http://www.intgovforum.org/cms/, retrieved 12 October 2012. 
The third metaphor, medium, shows up in discourses that address the internet as a new medium comparable to (though different from) conventional media. The specific affordances of 'new media' have been addressed in numerous publications from media and communication scholars. Commonly raised questions within this line of research include how the internet differs from previous media, its effect on the media ecosystem, and its ability to provide a structural alternative to current media powers. In the policy arena, a great amount of European internet policy speaks to the internet as a medium, which is reflected in commonly used notions such as harmful content, positive online content, media literary, protection of youth audiences, internet archiving and so forth. In other words, these notions would not be obvious from a public sphere perspective, which speaks of public discourse and democratic participation, rather than content and audiences. Neither would they describe the internet as a global resource, which is the focus of the infrastructure metaphor. With regard to social change the medium metaphor points to the internet as an open and participatory medium that democratizes access to publishing and broadcasting.

Finally, the culture metaphor shows up in literature and policy debates concerned with the social life that unfolds online and is reflected in notions such as cyberculture and cybercommunities. A large body of literature explores the internet from the perspective of social practices, focusing on the various examples of online communities, their entailed norms and values, collaborative practices, identity formation, means of self-regulation, and so forth. At policy level, a cultural take on the internet is presented among others by advocates of the free culture movement (Lessig 2004), who point to the practices of openness and sharing that occur online and argue that these practices conflict with conventional property rights regimes. The policy debates on these issues is ongoing at both UN and European level. In relation to social change, the culture metaphor highlights the potential of a more participatory culture.

\section{CASE STUDIES}

Two qualitative case studies are included in the book, addressing women's use of ICT in Uganda and the German Wikipedia. The studies are used to explore how local groups deploy and perceive communication technology as a resource for their respective courses, as well as to examine the involved actors' framing of their social practices in terms of the public sphere and the culture metaphors.

The case study research indicates an exploration of a phenomenon within its context, using a variety of data sources (Baxter and Jack 2008: 
544). The case study represents 'a phenomenon of some sort occurring in a bounded context' (Huberman and Miles 1994: 440). Case study research requires a close cooperation between the researcher and the participants, while encouraging the participants to share their views on the subject matter, for example via interview.

In the Uganda case study, the unit of analysis is the Women of Uganda Network (WOUGNET) and some of their partners, whereas the second study has the German Wikipedia community as the unit of analysis. In both cases qualitative interviews, field notes, observations, informal conversations, and analysis of various written material were used to provide a thick description of the case. ${ }^{22}$ In order to strengthen the validity of the case studies, the data material was examined for patterns and recurring arguments; multiple sources of evidence were included where possible; and key actors were asked to review the draft analysis. In order to ensure data reliability, the data collection was documented via recording and transcribing interviews, as well as by field notes (Yin 2009: 41).

The two case studies are essentially different in scope and context. Whereas the German Wikipedia study represents a loosely coupled community of individuals anchored in a virtual platform, the women's groups in Uganda share a physical base for action and deploy a mixture of conventional media and the internet. In addition, the women's groups are situated in a developing country characterized by poverty and limited access to the internet, while the German Wikipedia community represents wellconnected users in a Western country.

The choice of the Uganda case study to explore how the actors involved frame their social practices in terms of the public sphere metaphor, and the German Wikipedia to examine the culture metaphor, does not imply that the German Wikipedia could not have been examined from a public sphere perspective, and likewise the Uganda case from a cultural perspective. It does imply, however, that public sphere themes related to participation in public and political life resonate with the way the women's groups describe themselves and their mission. The same is true for themes related to online cultures, for example norms of openness and sharing, which have been associated with collaborative platforms such as Wikipedia by scholars and practitioners alike. The concluding chapter will illustrate how either case study might be approached from the perspective of infrastructure, public sphere, medium and culture, respectively.

22 The term 'thick description' refers to the method used by the anthropologist when he/she distils a description of a phenomenon from a complex set of practices (Geertz 1973: 382). 


\section{Data collection and analysis}

The qualitative data collection and analysis focused on how the actors involved experience, perceive, and explain their practices. The selection of interviewees followed a general approach of prioritizing people who where recommended as being engaged, open, knowledgeable or in some other way important in relation to the unit of analysis. The interviews were conducted in a semi-structured form using a thematic interview guide reflecting core issues associated with the public sphere and culture metaphor. The semi-structured format allowed for improvization and to track themes that appeared during the interview, including issues that were not part of the interview guide. Similarly there were themes that were relevant in some contexts but not in others, and that were therefore omitted in some interviews.

The data for the Uganda case study was collected during a field visit in the autumn of 2007, with some updates made in 2011 on the level of internet penetration in the country and with recent examples of online censorship. During the field visit 28 interviews were conducted with WOUGNET staff, the women involved in the rural access project in Apac, and a number of people working with or in relation to WOUGNET in Kampala. I also engaged in a number of more informal conversations. ${ }^{23}$ The majority of the 28 interviews were conducted with women and men engaged in WOUGNET, or member or partner organizations, rather than end users. As the main focus was on how local groups worked with and reflected on ICT as a resource for social change, the study prioritized people who represented a broad set of experiences with ICT at civil society level, rather than end users. I did meet with a group of local farmers in Apac, however; as the women only spoke the local language, Luo, the conversation had to be facilitated by an interpreter, and it was difficult to obtain very detailed answers.

The data collection for the Wikipedia case study was based on the large amount of text that the site in itself represents, and on seven qualitative interviews with people from the Berlin Wikipedia community, as well as a member of the Wikipedia Advisory Board, conducted in 2007 and 2009. The interviewees were recruited with a view to ensuring awareness of community norms and active participation in Wikipedia. The interviewees were identified by asking around in the community, and contacting people who were recommended as being engaged and knowledgeable Wikipedians. All

23 Please refer to Appendix B for an anonymous list of interviewed people/ groups. 
of those interviewed are experienced Wikipedia editors and several of them have been active in Wikipedia policy spaces, nationally as well as internationally. As such, the interviewees represent people who have been active in Wikipedia more or less since the beginning, and several of the interviewees have held positions of trust within the community. ${ }^{24}$

The data analysis was conducted by a combination of meaning condensation/coding and narrative structuring, employing a theme-based approach (Thagaard 2004: 158-63). As part of the analysis, theme-related points from the interview scripts were identified, and relevant examples and arguments collected. In order to retain some level of privacy on the part of those interviewed, while qualifying the findings to the widest extent possible, they are identified by affiliation but not by name.

${ }^{24}$ Please refer to Appendix $\mathrm{C}$ for an anonymous list of interviewed people/ groups. 
Rikke Frank Jørgensen - 9781782540809 Downloaded from PubFactory at 04/26/2023 08:22: 06 AM via free access 